\title{
ViewPoint: Upper Gastrointestinal Endoscopy in Malawi: An opportunity
}

\section{Will Howson}

Dept of Medicine, Queen Elizabeth Central Hospital, Blantyre

The introduction of endoscopy into Malawi both enables the re-evaluation of medical practice and opens many possibilities for research and future development of medical care. There are currently endoscopy units at Blantyre, Lilongwe and Zomba, and we hope and expect that in the future more units will be opened. Endoscopy units offer both upper and lower gastrointestinal (GI) examinations, although at present the vast majority of procedures performed in Malawi are studies of the upper GI tract.

\section{What is upper gastrointestinal endoscopy?}

Oesopho-gastro-duodenoscopy (OGD) involves the introduction of an endoscope, effectively a long flexible tube, through the pharynx into the oesophagus. The tube is controllable in two planes by the use of wheels; the operator has further control by use of rotation or "torque" of the endoscope. Traditionally endoscopes were fibreoptic, with fibres running the length of the tube transmitting the image to a camera attached next to the controls. Newer endoscopes have a video chip similar to that in many mobile phones, making the endoscope more robust. A light source illuminates the field of view, and two separate channels run the length of the tube: the first to enable washing of the mucosa and the lens at the front, the second for both for suction and the passage of instruments, such as snares, biopsy forceps and needles for injection. Thus the endoscope both provides macroscopic diagnostic information and can sample tissue for histopathological or microbiological analysis. In addition therapeutic techniques can be performed: ulcers can be injected through the biopsy channel, polyps removed, and varices injected or ligated with small rubber bands. In skilled hands it is possible to perform mucosal and sub mucosal dissection of large lesions, and separate tools are available for dilatation of strictures and the insertion of stents.

\section{Indications for upper GI endoscopy}

The major indication for OGD in Malawi, and indeed elsewhere, is for epigastric pain ${ }^{1,2}$. Here it is most commonly referred to as PUD or Peptic Ulcer Disease, though this is in fact a misnomer, as the vast majority of patients who are suspected to have PUD do not have an ulcer. Most commonly in these patients, OGD reveals evidence of gastritis. But a wide variety of other conditions may cause epigastric pain. In some of these the pain originates from the GI tract for example gastro-oesophageal reflux disease(GORD)and functional dyspepsia ${ }^{3}$ - and in others the source of pain is outside the gastrointestinal tract - eg biliary colic and chronic pancreatitis. The symptoms may vary only slightly between these different conditions, and very careful history-taking is crucial to try and differentiate between them.

\section{Gastritis}

In many patients OGD reveals gastritis, or inflammation of the lining of the stomach. It has a number of causes: drugs, infection (particularly $\mathrm{H}$ pylori) and other rarer conditions such as autoimmune disease. Medications known to cause gastritis include aspirin and the other drugs from the class of non steroidal anti-inflammatory drugs (NSAIDS) ${ }^{4}$, such as ibuprofen (Brufen), indomethacin (Indocid) and diclofenac.
These drugs can also cause ulceration of the gastric and duodenal mucosa. Patients with epigastric pain should therefore not be prescribed ibuprofen (currently a popular drug among prescribers), as it is likely to exacerbate their symptoms. One of the first interventions in any patient with epigastric pain is to stop any NSAIDs they may be taking.

\section{Helicobacter pylori}

$\mathrm{H}$ pylori is a spiral shaped Gram positive urease-producing bacterium. It lives under the layers of mucus in the gastric pits. It is found mostly in the gastric antrum, but can be elsewhere in both the stomach and duodenum. In patients who have been taking Proton Pump Inhibitors it migrates to the fundus 5 . H pylori is associated with lower socioeconomic status $^{6}$ and is thought to be acquired early in childhood, most probably from other family members ${ }^{7}$. The rates of $\mathrm{H}$ pylori carriage are thought to be high in Malawi ${ }^{8}$. In the longer term $\mathrm{H}$ pylori is associated with both peptic ulcer disease ${ }^{9}$ and gastric cancer ${ }^{10}$. In sub Saharan Africa, despite the known high rate of carriage of $\mathrm{H}$ pylori the rate of gastric cancers seems to be relatively low, a phenomenon which is unexplained $^{11}$. In addition some individuals with chronic $\mathrm{H}$ pylori infection develop atrophy of the gastric mucosa and achlorhydria $^{12}$. This may reduce the natural anti-bacterial effect of the stomach fluid and increase the risk of a variety of GI infections occurring. HIV is known to have a similar effect of raising gastric $\mathrm{pH}^{13}$ and it could be postulated that the HIV and H pylori may have a synergistic effect resulting in an increase in the susceptibility of an individual to infections such as Salmonella sp. The vast majority of patients with $\mathrm{H}$ pylori are asymptomatic carriers. Despite this, since it is known to be associated with dyspepsia, it seems sensible to give presumptive treatment in an attempt to eradicaten of $\mathrm{H}$ pylori in patients who present with suggestive symptoms, and only to resort to endoscopy in those whose symptoms persist. The exception to this is in patients with so called "red flag" symptoms, in whom OGD is indicated immediately. These symptoms are weight loss, dysphagia (difficulty swallowing), persistent vomiting, haematemesis or melena, and an epigastric mass; in these patients, as well as those aged over 55 with persistent symptoms, a referral for endoscopy is indicated ${ }^{14}$.

\section{Drug treatment for suspected $\mathbf{H}$ pylori infection}

Treatment for $\mathrm{H}$ pylori involves a combination of acidsuppression and antibiotics. This has classically been "triple therapy" a combination of a proton pump inhibitor (PPI) and two separate antibiotics. Currentlyin Malawi the recommended PPI is omeprazole and the antibiotics are amoxicillin $1 \mathrm{~g} b d$ and metronidazole $500 \mathrm{mg}$ bd. Metronidazole resistance in H. pylori in Malawi was described as being as high as $85 \%$ in Lilongwe ${ }^{8}$ and therefore patients are given two weeks of therapy rather than the standard seven days suggested by the British National Formulary. It is suspected, though currently not known, that there is a high rate of treatment failure among our patients on this therapy regimen. There are a number of alternatives. Exposure to metronidazole may be high in some sections of our population, and an alternative triple therapy regime that is soetimes effective is omeprazole, amoxicillin and clarithromycin. Higher rates of successful eradication have been described using a "quadruple therapy", which 
consists of adding bismuth chelate to the current regime. There have been reports of sequential dosing regimes but most of these make use of more expensive antibiotics not available in Malawi ${ }^{15}$.

\section{'Functional' dyspepsia}

Although there is an association between $\mathrm{H}$ pylori and epigastric pain, eradication does not necessarily result in an improvement in pain. A number of patients who have had successful eradication still have ongoing symptoms ${ }^{16}$. This group is often described as having functional dyspepsia, or non-ulcer dyspepsia. As with all functional bowel disease, the symptoms are common and result in frequent consultations to medical services. This condition is not associated with any increase in mortality. The prevalence and incidence of this condition in Malawi are unknown, but experience in the clinic and endoscopy unit suggest that it is common.

\section{Other causes of dyspeptic symptoms}

It would be interesting to investigate what other causes of epigastric pain occur commonly in Malawi and should be more routinely considered in the differential diagnosis. Abdominal tuberculosis can present with abdominal pain ${ }^{17}$ : no one knows the incidence of this disease in our population, although with the increase in extra pulmonary tuberculosis in HIV-infected people it might be expected to be rising. Similarly in schistosomiasis due to $\mathrm{S}$ mansoni, which is common here, the presence of adult worms in mesenteric veins or the passage of ova through the wall of the gut might be associated with epigastric discomfort.

\section{Conclusion}

The development of endoscopy services in Malawi offers the chance of improving patient care and raises a number of questions about the way we treat common symptoms. Endoscopy has shown that what clinicians suspect to be Peptic Ulcer Disease rarely is. It will hopefully become clearer in the future what associations there are between $\mathrm{H}$ pylori and other diseases, and what are the best treatment options. Meanwhile endoscopy plays an important role in excluding peptic ulcer disease in many patients and identifying it in a few, and in making a range of other diagnoses.

\section{Addendum}

Endoscopy has an increasing role in the treatment of other conditions such as oesophageal varices, which will be the subject of another article in this series.

\section{References}

1.Olokoba $\mathrm{AB}$, Bojuwoye $\mathrm{BJ}$. Indications for oesophagogastroduodenoscopy in Ilorin, Nigeria--a 30 month review. Niger J Clin Pract. 2010 Sep;13(3):260-3

2. Cooper GS. Indications and contraindications for upper gastrointestinal endoscopy. Gastrointest Endosc Clin N Am. 1994 Jul;4(3):439-54

3. Tosetti C, Bellentani S, Benedetto E, et al The management of patients with new onset of upper gastro-intestinal symptoms in primary care. Dig Liver Dis. 2010 Dec;42(12):860-4

4.Thiéfin G, Schaeverbeke T, Barthélémy P, Soufflet C, Flipo RM Upper gastrointestinal symptoms in patients treated with nonsteroidal anti-inflammatory drugs: prevalence and impact--the COMPLAINS study. Eur J Gastroenterol Hepatol. 2010 Jan;22(1):81-7

5.Logan RP, Walker MM, Misiewicz JJ, Gummett PA, Karim QN, Baron JH. Changes in the intragastric distribution of Helicobacter pylori during treatment with omeprazole. Gut. 1995 Jan;36(1):12-6.

6.Bardhan PK. Epidemiological features of Helicobacter pylori infection in developing countries. Clin Infect Dis. 1997;25:973-978.

7.Weyermann $\mathrm{M}$, Rothenbacher $\mathrm{M}$, Brenner $\mathrm{H}$, Acquisition of Helicobacter Pylori Infection in Early Childhood: Independent Contributions of Infected Mothers, Fathers, and Siblings Am J Gastroenterol 2009; 104:182-189.

8.Harries AD, Stewart M, Deegan KM, Mughogho GK, Wirima JJ, Hommel M, Hart CA. Helicobacter pylori in Malawi, central Africa. J Infect. 1992 May;24(3):269-76.

9.Marshall BJ, Goodwin CS, Warren JR, et al. Prospective doubleblind trial of duodenal ulcer relapse after eradication of Campylobacter pylori. Lancet 1988;ii: 1467-9.

10.Helicobacter and Cancer Collaborative Group. Gastric cancer and Helicobacter pylori: a combined analysis of 12 case control studies nested within prospective cohorts. Gut. 2001;49:347-353.

11.Holcombe C. Helicobacter pylori: the African enigma.Gut. 1992 April; 33(4): 429-431.

12.Ruiz B, Correa P, Fontham ET, Ramakrishnan T. Antral atrophy, Helicobacter pylori colonization, and gastric pH. Am J Clin Pathol 1996; 105: 96-101.

13.Belitsos PC, Greenson JK, Yardley JH, Sisler JR, Bartlett JG. Association of gastric hypoacidity with opportunistic enteric infections in patients with AIDS. J Infect Dis. 1992 Aug;166(2):277-84.

14.http://www.nice.org.uk/nicemedia/live/10950/29458/29458.pdf

15.Gao XZ, Qiao XL, Song WC, Wang XF, Liu F. Standard triple, bismuth pectin quadruple and sequential therapies for Helicobacter pylori eradication. World J Gastroenterol. 2010 Sep 14;16(34):435762.

16.Harvey RF, Lane JA, Nair P, Egger M, Harvey I, Donovan J, Murray L. Clinical trial: prolonged beneficial effect of Helicobacter pylori eradication on dyspepsia consultations - the Bristol Helicobacter Project. Aliment Pharmacol Ther. 2010 Aug;32(3):394-400

17.Chou CH, Ho MW, Ho CM, Lin PC, Weng CY, Chen TC, Chi CY, Wang JH. Abdominal tuberculosis in adult: 10-year experience in a teaching hospital in central Taiwan. J Microbiol Immunol Infect. 2010 Oct;43(5):395-400. 